\title{
Analysis of Flatness Deviations for Austenitic Stainless Steel Workpieces after Efficient Surface Machining
}

\author{
K. Nadolny ${ }^{1}$, W. Kapłonek ${ }^{2}$ \\ ${ }^{1}$ Department of Production Engineering, Faculty of Mechanical Engineering, Koszalin University of Technology, \\ Racławicka 15-17, 75-620, Koszalin, Poland, krzysztof.nadolny@tu.koszalin.pl \\ ${ }^{2}$ Subject Group of Metrology and Quality, Department of Production Engineering, Faculty of Mechanical Engineering, \\ Koszalin University of Technology, Racławicka 15-17, 75-620, Koszalin, Poland, wojciech.kaplonek@tu.koszalin.pl
}

\begin{abstract}
The following work is an analysis of flatness deviations of a workpiece made of X2CrNiMo17-12-2 austenitic stainless steel. The workpiece surface was shaped using efficient machining techniques (milling, grinding, and smoothing). After the machining was completed, all surfaces underwent stylus measurements in order to obtain surface flatness and roughness parameters. For this purpose the stylus profilometer Hommel-Tester T8000 by Hommelwerke with HommelMap software was used. The research results are presented in the form of 2D surface maps, 3D surface topographies with extracted single profiles, Abbott-Firestone curves, and graphical studies of the $S k$ parameters. The results of these experimental tests proved the possibility of a correlation between flatness and roughness parameters, as well as enabled an analysis of changes in these parameters from shaping and rough grinding to finished machining. The main novelty of this paper is comprehensive analysis of measurement results obtained during a three-step machining process of austenitic stainless steel. Simultaneous analysis of individual machining steps (milling, grinding, and smoothing) enabled a complementary assessment of the process of shaping the workpiece surface macro- and micro-geometry, giving special consideration to minimize the flatness deviations.
\end{abstract}

Keywords: Flatness errors, stylus profilometry, surface topography analysis, austenitic stainless steel, surface machining.

\section{INTRODUCTION}

$\mathrm{O}$ NE OF THE CHALLENGES that machine and device parts producers face nowadays is the necessity to guarantee a high quality of machined surfaces. Obtaining a high quality product is an extremely difficult and complex task that entails fulfilling a number of crucial requirements. They are related not only to the production process itself but also to using a wide spectrum of measurement procedures. These procedures are used to control the measurement correctness of certain elements and to guarantee their proper geometrical structure and shape-dimensional repeatability, making it possible to maintain proper utility and service parameters during their whole operating life.

One of the most important properties of the surface texture, which should be guaranteed after a properly carried out machining process, is its proper flatness [1]-[2]. As obtaining perfect surface flatness in manufacturing conditions is impossible, the notion of flatness deviation is used [3]. The classic definition of flatness deviation (included, among others, in a standard already withdrawn in Poland [4]) reads that there is the greatest distance of the real surface points from the plane adjacent to the area of the partial field. The adjacent plane was in this case a surface in the shape of a nominal plane which touches upon the real surface on the outside of the material. This meant that the distance between the adjacent plane and the farthest real surface point within the borders of the partial field was the lowest value. The standards currently in force [5]-[6] offer definitions of all geometric elements necessary for proper determination of the flatness deviation (e.g., the nominal plane, real plane, the reference plane and others), as well as definitions of their proper parameters. These parameters will be described in more detail in Section 2.

\section{CHARACTERISTICS OF FLATNESS ERROR PARAMETERS}

In the assessment of flatness deviation the ISO document [7] defines a number of parameters such as:

- FLTt (peak-to-valley flatness deviation (MZPL), (LSPL)),

- FLTp (peak-to-reference flatness deviation (LSPL)),

- FLTv (reference-to-valley flatness deviation (LSPL))

- FLTq (root mean square flatness deviation (LSPL)).

Note: MZPL - Minimum Zone Reference Planes, LSPL Least Squares Reference Plane.

Experience in a real production environment showed that the most useful of these parameters, from metrological point of view, is FLTt - peak-to-valley flatness deviation [8]. This parameter is defined as the value of the largest positive local flatness deviation added to the absolute value of the largest negative local flatness deviation (established for the reference plane determined by the Minimum Zone Method (MZM) [9]-[10] as well as Least Squares Method (LSM) [11]-[12]. The MZM is characterized by higher accuracy, however, the LSM is more useful to evaluate the flatness deviation of the profiles due to the relatively simple method of determining the reference plane. This is due to the fact that LSM is more eagerly applied due to the relatively easy implementation, and higher computational efficiency. The main disadvantage of this method is that LSM does not guarantee the Minimum Zone Criterion (MZC) [13], which is specified in the standard [14], as well as it often overestimates the tolerances. Using this plane, determined by the LSM, the dependence on the flatness deviation can be written in the following form:

$$
F L T t=F L T p+F L T v
$$

where: FLTp - value of the largest positive local flatness deviation from the LSPL, FLTV - absolute value of the largest negative local flatness deviation from the LSPL. 
In flatness measurements the adoption of an appropriate reference plane is a key issue [15]. In many cases, the reference plane is defined by LSM. Adopted with respect to this plane, the FLTq parameter is defined as the square root of the sum of the squares of the local flatness deviations from the LSPL.

The FLTq parameter is determined from the following equation:

$$
\text { FLTq }=\sqrt{\frac{1}{A}} \int_{A} L F D^{2} d A
$$

where: $L F D$ - local flatness deviation; A - surface area of the flatness feature.

\section{SURFACE MACHINING}

The aim of the experimental tests was to look for a possible increase in the efficiency of finish grinding of flat surfaces made of stainless steel.

The surface machining was carried out in three stages:

- Stage I: milling;

- Stage II: grinding;

- Stage III: smoothing.

The condition of the machined surface was analyzed after each of the above-mentioned operations, with its flatness deviation being evaluated and roughness parameters, on the basis of the registered microtopographies, determined.

\subsection{Workpiece material.}

The workpiece was a metal plate made from $\mathrm{X} 2 \mathrm{CrNiMo}$ 17-12-2 austenitic stainless steel [16]-[17] and sized 150× $150 \times 20 \mathrm{~mm}$, whose characteristics are presented in Table 1 .

Table 1. The abbreviated characteristics of austenitic stainless steel X2CrNiMo17-12-2* [18].

\begin{tabular}{|c|c|c|}
\hline Material No. & Standard & $\begin{array}{c}\text { Chemical } \\
\text { composition }[\%]\end{array}$ \\
\hline 1.4404 & $\begin{array}{c}\text { PN-00H17N14M2 } \\
\text { AISI 316L } \\
\text { UNS S 31603 } \\
\text { BS 316S11 } \\
\text { JIS SUS316 } \\
\text { DIN } 174401.4404 \\
\text { SIS } 2348\end{array}$ & $\begin{array}{l}\text { Cr (16.50-18.50), } \\
\text { Ni (10.50-13.00), } \\
\text { C (0.030 max.), } \\
\text { Si (1.00 max.), } \\
\text { Mn (2.00 max.), } \\
\text { Mo (2.00-2.50), } \\
\text { N (0.050 max.), } \\
\text { P (0.030 max.), } \\
\text { S (0.010 max.), } \\
\text { Fe (Remainder) }\end{array}$ \\
\hline $\begin{array}{c}\text { Mechanical } \\
\text { property }\end{array}$ & At $20-25^{\circ} \mathrm{C}$ & At $150^{\circ} \mathrm{C}$ \\
\hline $\begin{array}{l}\text { Tensile strength } \\
\mathrm{Rm}, \mathrm{MPa}\end{array}$ & 585 (min.) & 525 (min.) \\
\hline $\begin{array}{l}\text { Yield stress } \\
\text { Rp } 0.2 \%, \mathrm{MPa}\end{array}$ & 260 (min.) & 230 (min.) \\
\hline $\begin{array}{l}\text { Young's modulus } \\
\text { E, GPa }\end{array}$ & 200 (min.) & 186 (min.) \\
\hline $\begin{array}{l}\text { Elongation at } \\
\text { break A5, \% }\end{array}$ & 35 (min.) & - \\
\hline $\begin{array}{l}\text { Brinell hardness } \\
\text { HB }\end{array}$ & 180 (max.) & - \\
\hline
\end{tabular}

*Material is produced by The Deutsche Edelstahlwerke GmbH (Germany).

\subsection{Machining methodology.}

Milling of the top and bottom surfaces, as well as the workpiece edges, was carried out with a console vertical milling machine of FYF32J type, produced by the Jarocin Machine-Tools Factory JAFO JSC (Poland).

Grinding of the top surface of the workpiece after milling was carried out with a grinder for plates with a vertical spindle axis on a grinding wheel of SAC-30 type, produced by the JOTES Machinery Factory LLC (Poland).

Smoothing of the workpiece surface layer after grinding was carried out using a tool grinder with a horizontal spindle axis on a grinding wheel of US 2305 type by Jungner R.M. AB (Sweden).

Table 2. compares the most important machining parameters used in the three subsequent stages of the flat surface shaping process.

Table 2. Surface machining parameters $\left(n_{c}-\right.$ tool rotational frequency, $v_{f t}$-tangential table feed speed, $a_{p}$-back engagement).

\begin{tabular}{|l|l|l|}
\hline \multicolumn{1}{|c|}{$\begin{array}{c}\text { Step I: } \\
\text { The Milling }\end{array}$} & $\begin{array}{c}\text { Step II: } \\
\text { The Grinding }\end{array}$ & \multicolumn{1}{c|}{$\begin{array}{c}\text { Step III: } \\
\text { The Smoothing }\end{array}$} \\
\hline & $\begin{array}{l}\text { Tool: segmented } \\
\text { grinding wheel }\end{array}$ & Tool: abrasive \\
Tool: shell end & $n_{c}=1450 \mathrm{rpm}$ & disc $3 \mathrm{M}$ XL-RD \\
mill NFCa 80 & $v_{f t}=30 \mathrm{~m} / \mathrm{min}$. & $3 \mathrm{~S}-\mathrm{FIN}$ \\
$n_{c}=112 \mathrm{rpm}$ & $a_{p}=0.1 \mathrm{~mm}$ & $n_{c}=3000 \mathrm{rpm}$ \\
$v_{f t}=45 \mathrm{~mm} / \mathrm{min}$. & Number of & $v_{f t}=$ manual \\
$a_{p}=1.0 \mathrm{~mm}$ & passages: until & $a_{p}=0.05 \mathrm{~mm}$ \\
Coolant: $5 \%$ & spark-out & Number of \\
water solution of & Coolant: $5 \%$ & passages: until \\
Castrol Syntilo & water solution of & spark-out \\
RHS oil & Castrol Syntilo & Coolant: none \\
& RHS oil & \\
\hline
\end{tabular}

\section{MEASUREMENT INSTRUMENT AND METHODOLOGY}

The surface microtopography measurements of the workpiece after machining were carried out using the stylus profilometer Hommel-Tester T8000 produced by Hommelwerke GmbH (Germany). The instrument, presented in Fig.1., was equipped with a TKL100 pick-up with a diamond stylus tip (tip radius $r=2.5 \mu \mathrm{m}$ ). HommelTester T8000 used traverse unit Waveline ${ }^{\mathrm{TM}} 60$ Basic

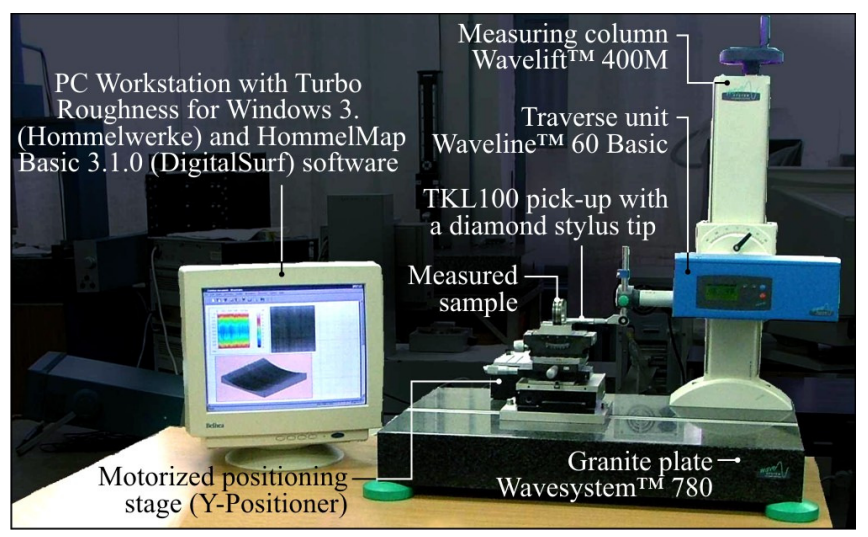

Fig.1. Stylus profilometer Hommel-Tester T8000 produced by Hommelwerke GmbH (Germany) used in the experimental tests. 
(tracing length $l=60 \mathrm{~mm}$ ), which was mounted on a measuring column Wavelift ${ }^{\mathrm{TM}} 400 \mathrm{M}$ (max. traverse $l_{\max }=400 \mathrm{~mm}$ ). The column was, in turn, mounted on a granite plate Wavesystem ${ }^{\mathrm{TM}} 780$. In the plate was a groove for mounting a motorized positioning stage (Y-Positioner) equipped with a stepper motor, intended to carry out precise movements in the $y$-axis.

All microtopographies were registered for a $4.8 \times 4.8 \mathrm{~mm}$ surface area. The measurement was made in 241 passes with a sampling step of $20 \mu \mathrm{m}$ in single-pass mode, i.e., registration of data took place only in one direction on the measured surface. In a single pass approximately 4,000 points were registered with the tracing speed $V=0.15 \mathrm{~mm} / \mathrm{s}$.

The stylus profilometer used two types of software. Turbo Roughness for Windows 3.1 was used for the control of measuring elements as well as for setting conditions for measurements. For analysis and visualization of the obtained measurement data HommelMap Basic 3.1.0, using Mountain Technology ${ }^{\mathrm{TM}}$ provided by DigitalSurf (France), was used.

\section{MEASUREMENT RESULTS AND DISCUSSION}

The section below presents select results from the experimental tests carried out on the workpiece surface (metal plate made from austenitic stainless steel $\mathrm{X} 2 \mathrm{CrNi}$ Mo17-12-2 sized $150 \times 150 \times 20 \mathrm{~mm}$ ) after completion of the milling, grinding and smoothing processes. Due to the relatively large number of results obtained, the authors decided to present only a selection. This selection may be treated as a representative example of the obtained measurement data.

The results were compared in three large analysis groups (one for each machining technique respectively), presented in Figs.2-4. Each group contains the following elements:

- a 2D surface map in indexed colors, where the roughness height is encoded with the proper color;

- a Photo simulation (visualization in "simulated photographic" mode);

- a 3D surface topography after the roughness filtration (Gaussian filter, cut-off $0.8 \mathrm{~mm}$ ), extracting single profiles and calculated flatness parameters (in accordance with [7]);

- a 3D surface topography after the waveness filtration (Gaussian filter, cut-off $0.8 \mathrm{~mm}$ ) and calculated amplitude, hybrid and functional parameters of surface roughness;

- A set of selected parameters from the amplitude, hybrid and functional group are characterized in Table 3.

The above stated elements were additionally supplemented with substantial data concerning the measurement conditions and the general overview of machining setups. Fig.2. presents the results obtained for the surface after milling. Their analysis shows that it is possible to obtain a surface roughness, in this operation, expressed with the parameter $S a=0.742 \mu \mathrm{m}$, with the value of the parameter describing the peak-to-valley surface deviation $F L T t=0.996 \mu \mathrm{m}$. The high values of the above stated parameters and the ones whose values can be read in Fig.2. have their explanation in the type of machining process selected. Milling needs to be treated in this case as rough grinding. It leaves behind clearly visible machining marks with roughness of about 7-8 $\mu \mathrm{m}$. Analysis of the height of these marks may be done
Table 3. The characteristics of calculated parameters of surface microtopography.

\begin{tabular}{|c|c|l|}
\hline Group & Parameter $^{*}$ & \multicolumn{1}{c|}{ Name } \\
\hline \multirow{4}{*}{ Amplitude } & $S a^{* *}$ & $\begin{array}{l}\text { Arithmetic mean deviation } \\
\text { of the surface }\end{array}$ \\
\cline { 2 - 3 } & $S t^{* *}$ & Total height of the surface \\
\cline { 2 - 3 } & $S q^{* *}$ & $\begin{array}{l}\text { Root-Mean-Square (RMS) } \\
\text { deviation of the surface }\end{array}$ \\
\cline { 2 - 3 } & $S p^{* * *}$ & Maximum height of summits \\
\cline { 2 - 3 } Hybrid & $S v^{* * *}$ & Maximum depth of valleys \\
\hline \multirow{5}{*}{ Functional } & $S d r$ & Developed interfacial area ratio \\
\cline { 2 - 3 } & $S k$ & $\begin{array}{l}\text { Kernel roughness depth } \\
\text { (roughness depth of the core) }\end{array}$ \\
\cline { 2 - 3 } & $S p k$ & $\begin{array}{l}\text { Reduced peak height } \\
\text { (roughness depth of the peaks) }\end{array}$ \\
\cline { 2 - 3 } & $S v k$ & $\begin{array}{l}\text { Reduced valley depth } \\
\text { (roughness depth of the valleys) }\end{array}$ \\
\cline { 2 - 3 } & $S r 1$ & Upper material ratio \\
\cline { 2 - 3 } & $S r 2$ & Lower material ratio \\
\hline
\end{tabular}

${ }^{*}$ All parameters are included in the EUR $15178 \mathrm{EN}$ report [19], ${ }^{* *}$ primary amplitude parameter, ${ }^{* * *}$ secondary amplitude parameter.

using Fig.2.a-c and Fig.2.e. The flatness parameters were determined from 3D surface topography after the roughness filtration (Gaussian filter, cut-off $0.8 \mathrm{~mm}$ ) and presented in Fig.2.d. Single profiles presented on the right side of the figure were extracted from three randomly selected places. Depending on the surface shaping, the profile elements' heights were in the range of $\pm 4.5 \mu \mathrm{m}$. After milling, the surfaces underwent grinding, whose job was to remove the machining marks left after milling and decrease roughness, as well as surface flatness deviation, before the final smoothing procedure.

A comparison of the results for this machining is presented in Fig.3. The results of grinding with a segmented grinding wheel with grinding segments made from a relatively large abrasive (size 60) of polycrystalline white-fused alumina 99A, provide over three times the reduction of surface roughness to the value $S a=0.226 \mu \mathrm{m}$ and a minor decrease of the peakto-valley flatness deviation $F L T t=0.826 \mu \mathrm{m}$. Values of the other parameters were also decreased due to the finish grinding. Analysis of the profiles singled out (Fig.3.d.) made it possible to determine the heights of their elements. In this case the values were in the range of $\pm 0.1 \mu \mathrm{m}$.

The operation of grinding left clear machining marks as high as 5-6 $\mu \mathrm{m}$ (Fig.3.a-c and Fig.3.e) on the workpiece surface. These marks had to be removed in the final machining stage - the smoothing.

For the smoothing operation it was decided that a disc produced by the $3 \mathrm{M}$ (USA), whose trade name is XL-RD and is made from pressed abrasive fabric, was used as an abrasive tool. The selected characteristics of this tool (3S-FIN) corresponded to and made fabric of average hardness with abrasive grains of silica carbide, used for finish grinding (P400-P600).

As a result of the fabric's flexibility, in the applied machining system it was impossible to meet the demands of surface flatness. Moreover, the tool turned out to be definitely too large-grained (the values stated by the producer deviated from the observed machining results). As a consequence, the disc ground rather than smoothed the surface. 


\section{D SURFACE MAP | PHOTO-SIMULATION | CONTOUR DIAGRAM}

a)

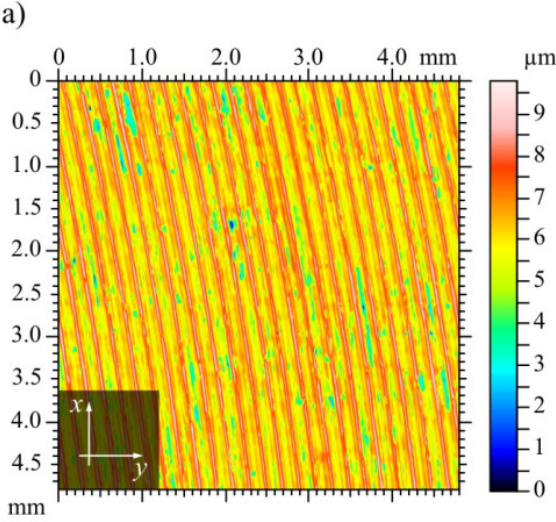

b)

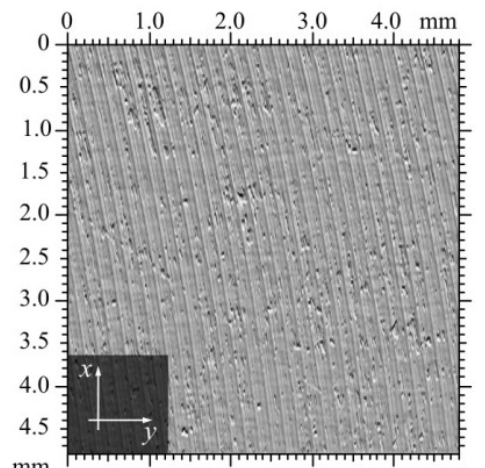

c)

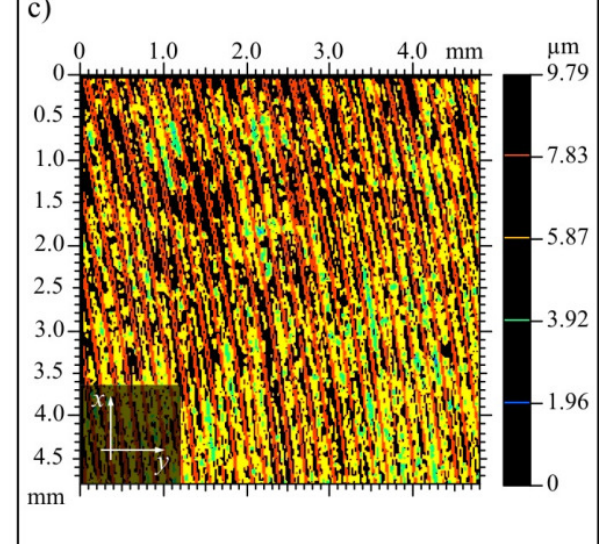

\section{D SURFACE MICROTOPOGRAPHY WITH EXTRACTED ROUGHNESS AND WAVINESS}

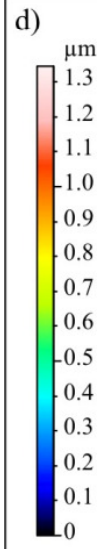

d) $\begin{aligned} & \mu \mathrm{m} \\ & 1.3 \\ & 1.2 \\ & 1.1 \\ & -1.0 \\ & 0.9 \\ & 0.8 \\ & 0.7 \\ & 0.6 \\ & -0.5 \\ & 0.4 \\ & 0.3 \\ & 0.2 \\ & 0.1 \\ & 0\end{aligned}$

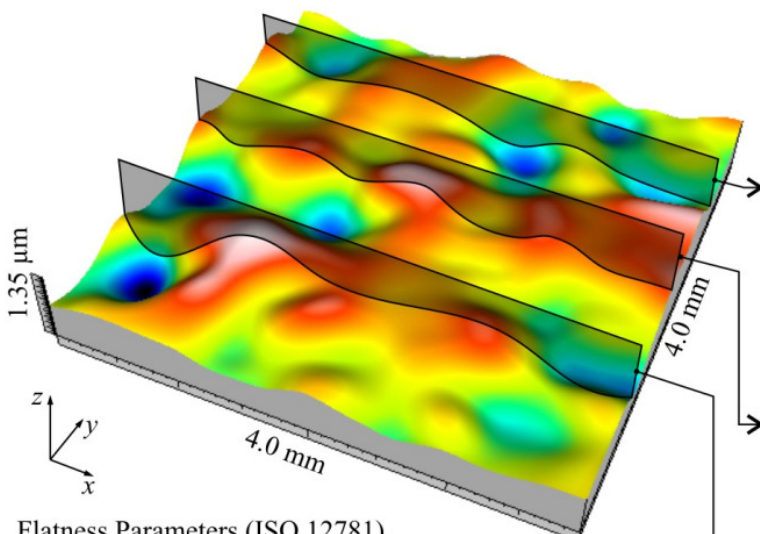

$\mu \mathrm{m} \uparrow \quad$ Length $=4 \mathrm{~mm} P t=0.504 \mu \mathrm{m}$ Scale $=1 \mu \mathrm{m}$

Flatness Parameters (ISO 12781)

LSPL, Gaussian Filter, $0.8 \mathrm{~mm}$

$F L T t=0.996 \mu \mathrm{m}$

$F L T p=0.422 \mu \mathrm{m}$

$F L T v=0.574 \mu \mathrm{m}$

e)

$F L T q=0.162 \mu \mathrm{m}$
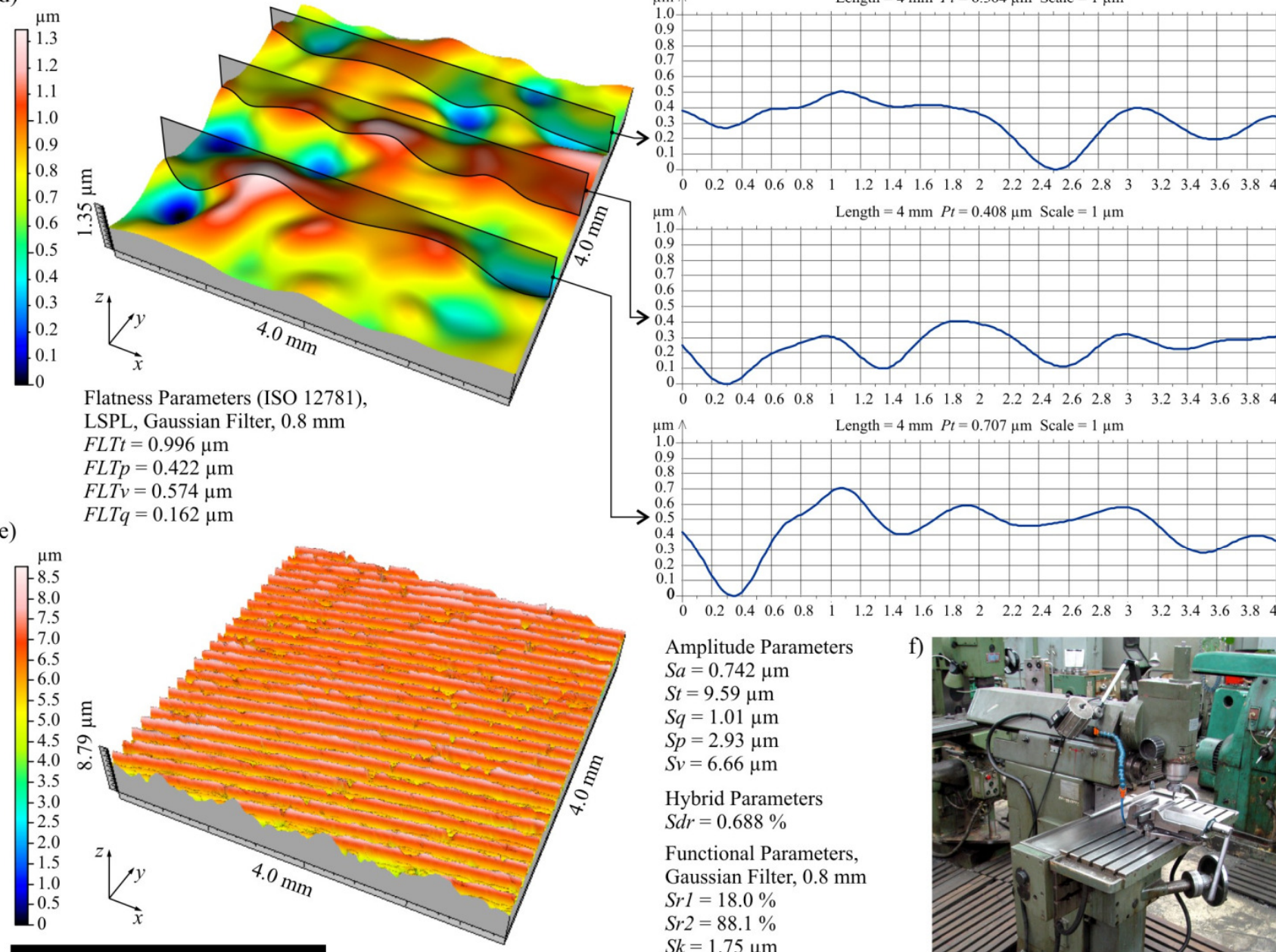

0.7

0.6

0.5
0.3

0.2

$\begin{array}{llllllllllllllllllllllllll}0 & 0.2 & 0.4 & 0.6 & 0.8 & 1 & 1.2 & 1.4 & 1.6 & 1.8 & 2 & 2.2 & 2.4 & 2.6 & 2.8 & 3 & 3.2 & 3.4 & 3.6 & 3.8 & 4 \mathrm{~mm}\end{array}$

$\mu \mathrm{m} \uparrow \quad$ Length $=4 \mathrm{~mm} P t=0.408 \mu \mathrm{m}$ Scale $=1 \mu \mathrm{m}$

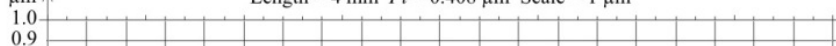

0.8

\begin{tabular}{r|r}
0.8 \\
0.7 \\
0.6
\end{tabular}

0.3

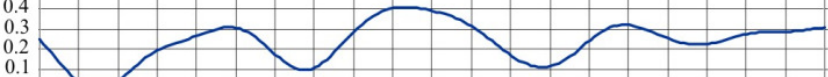

0 ,

$\begin{array}{llllllllllllll}0.2 & 0.4 & 0.6 & 0.8 & 1 & 1.2 & 1.4 & 1.6 & 1.8 & 2 & 2.2 & 2.4 & 2.6 & 2.8 \\ \text { Length }=4 & 4 \mathrm{~mm} \quad P t=0.707 \mu \mathrm{m} \text { Scale }=1 \mu \mathrm{m}\end{array}$

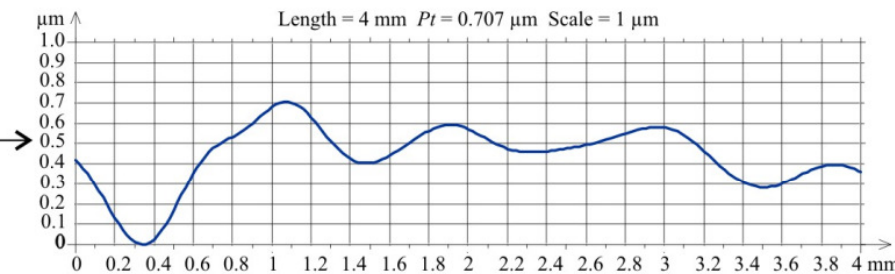

$\begin{array}{llllllllllllllllllllllllllllllll}0 & 0.2 & 0.4 & 0.6 & 0.8 & 1 & 1.2 & 1.4 & 1.6 & 1.8 & 2 & 2.2 & 2.4 & 2.6 & 2.8 & 3 & 3.2 & 3.4 & 3.6 & 3.8 & 4\end{array}$

Amplitude Parameters

$S a=0.742 \mu \mathrm{m}$

$S t=9.59 \mu \mathrm{m}$

$S q=1.01 \mu \mathrm{m}$

$S p=2.93 \mu \mathrm{m}$

$S v=6.66 \mu \mathrm{m}$

Hybrid Parameters

$S d r=0.688 \%$

Functional Parameters,

Gaussian Filter, $0.8 \mathrm{~mm}$

$\operatorname{Sr} 1=18.0 \%$

$\operatorname{Sr} 2=88.1 \%$

$S k=1.75 \mu \mathrm{m}$

\section{MESUREMENT CONDITIONS}

Measured surface area (axes x, y, z): 4.8×4.8×0.00979 mm | The number of profile points (axis x): 3994 | Distance between profile points (axis x): $1.2 \mu \mathrm{m}$ | The number of profiles (axis y): 241 | Distance between profile points (axis y): $20 \mu \mathrm{m}$ | Vertical resolution (axis z): $0.001 \mu \mathrm{m}$ | Measuring speed: $0.15 \mu \mathrm{m} / \mathrm{s}$ | Measuring time: $5442 \mathrm{~s}$

Fig.2. Collection of select results of experimental tests carried out for a workpiece surface made of X2CrNiMo17-12-2 austenitic stainless steel after the milling process, obtained by stylus profilometer Hommel-Tester T8000 produced by Hommelwerke with HommelMap Basic 3.1.0 software: a) 2D surface map (indexed colors), b) photo simulation, c) contour diagram, d) 3D surface topography after the roughness filtration with calculated flatness parameters of the individual extracted profiles, e) 3D surface topography after the waveness filtration and calculated amplitude, hybrid and functional parameters of surface roughness, f) general view of the machining setup. 


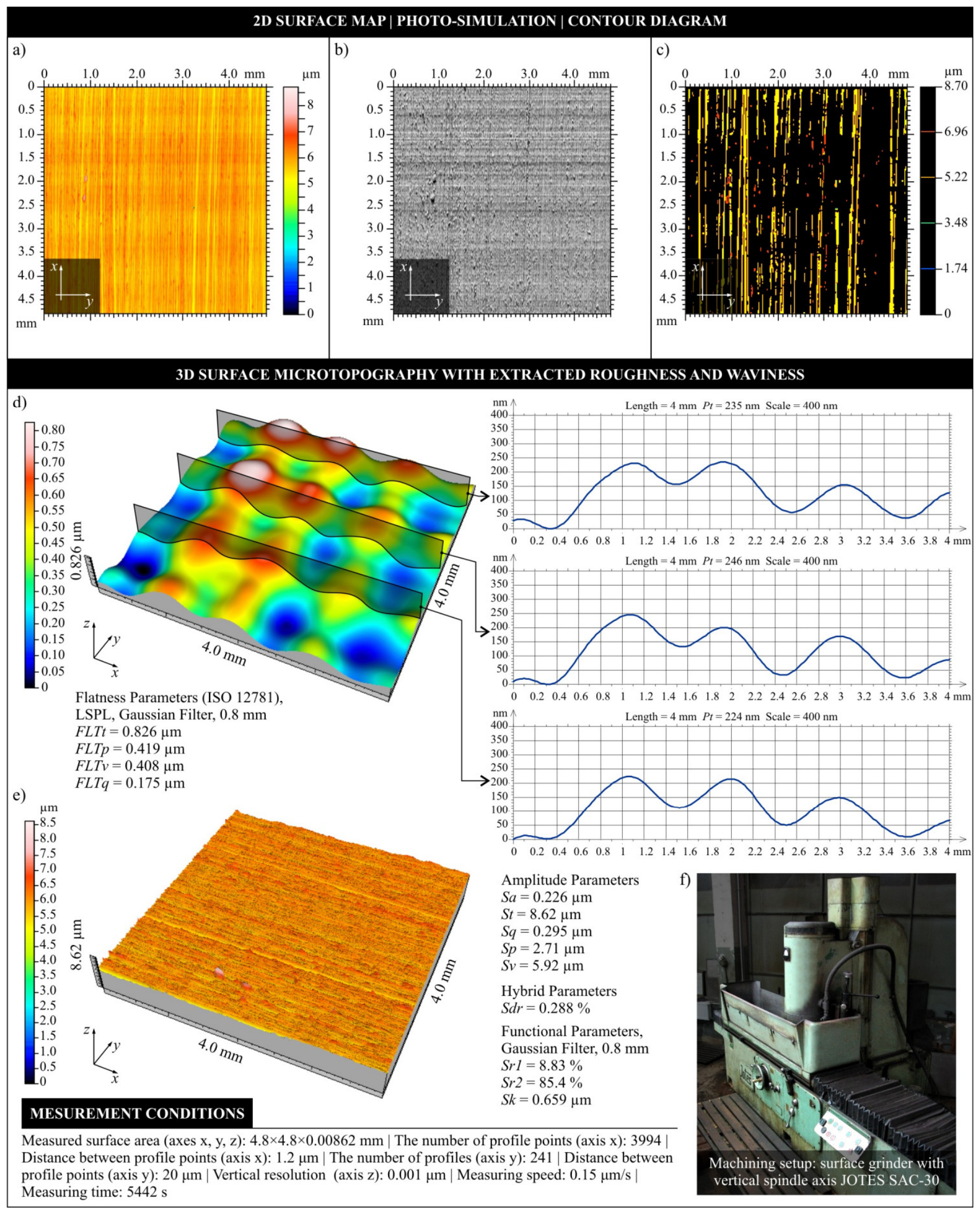

Fig.3. Collection of select results of experimental tests carried out for a workpiece surface made of X2CrNiMo17-12-2 austenitic stainless steel after the grinding process, obtained by stylus profilometer Hommel-Tester T8000 produced by Hommelwerke with HommelMap Basic 3.1.0 software: a) 2D surface map (indexed colors), b) photo simulation, c) contour diagram, d) 3D surface topography after the roughness filtration with calculated flatness parameters of the individual extracted profiles, e) 3D surface topography after the waviness filtration and calculated amplitude, hybrid and functional parameters of surface roughness, f) general view of the machining setup. 
2D SURFACE MAP | PHOTO-SIMULATION | CONTOUR DIAGRAM

a)

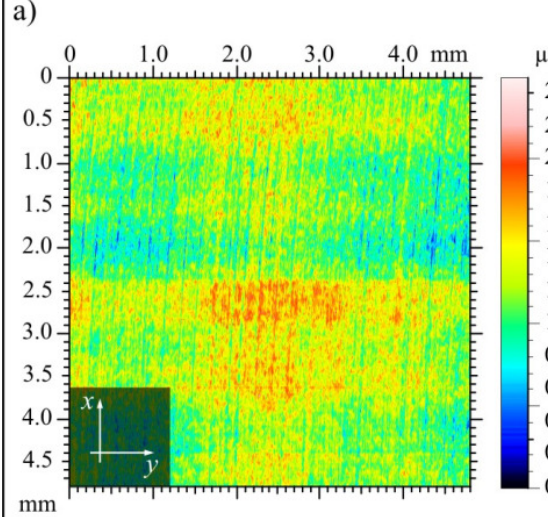

b)

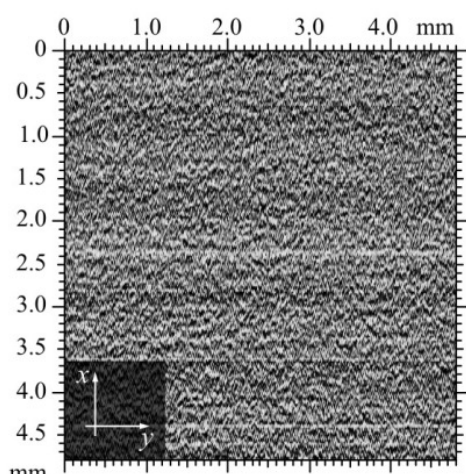

c)

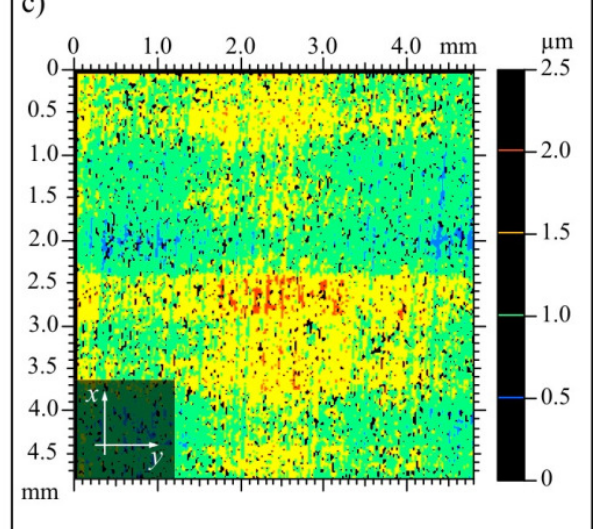

\section{D SURFACE MICROTOPOGRAPHY WITH EXTRACTED ROUGHNESS AND WAVINESS}

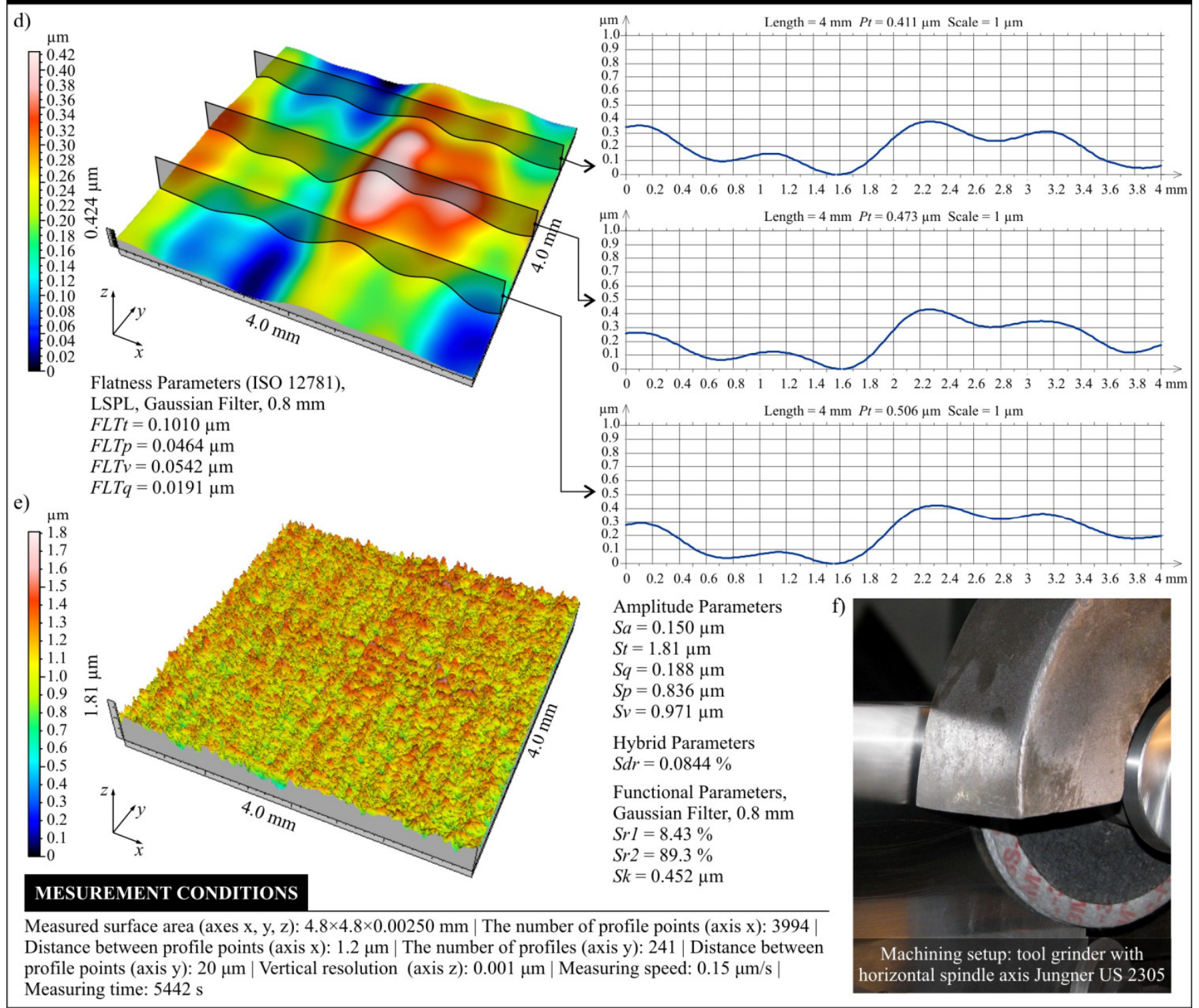

Fig.4. Collection of select results of experimental tests carried out for a workpiece surface made of X2CrNiMo17-12-2 austenitic stainless steel after the smoothing process, obtained by stylus profilometer Hommel-Tester T8000 produced by Hommelwerke with HommelMap Basic 3.1.0 software: a) 2D surface map (indexed colors), b) photo simulation, c) contour diagram, d) 3D surface topography after the roughness filtration with calculated flatness parameters of the individual extracted profiles, e) 3D surface topography after the waviness filtration and calculated amplitude, hybrid and functional parameters of surface roughness, f) general view of the machining setup. 


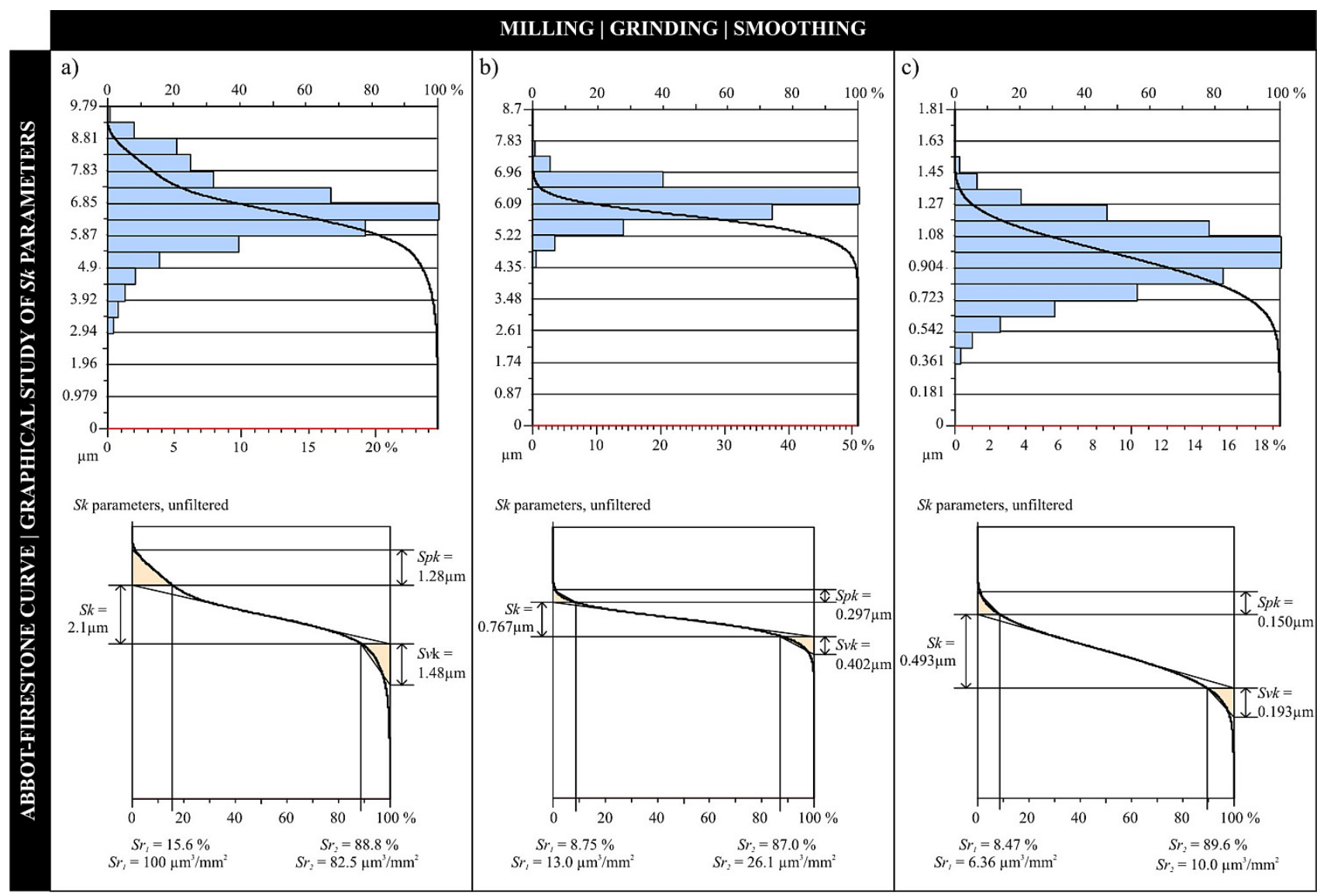

Fig.5. Collection of select results of experimental tests carried out for workpiece surface made of X2CrNiMo17-12-2 austenitic stainless steel obtained by stylus profilometer Hommel-Tester T8000 produced by Hommelwerke with HommelMap Basic 3.1.0 software in the form of an Abbott-Firerstone curve (top) and graphical studies of $S k$ parameters (bottom) after the: a) milling process, b) grinding process, c) smoothing process.

\section{FLUCTUATIONS OF THE FLATNESS / ROUGHNESS PARAMETERS}

a)

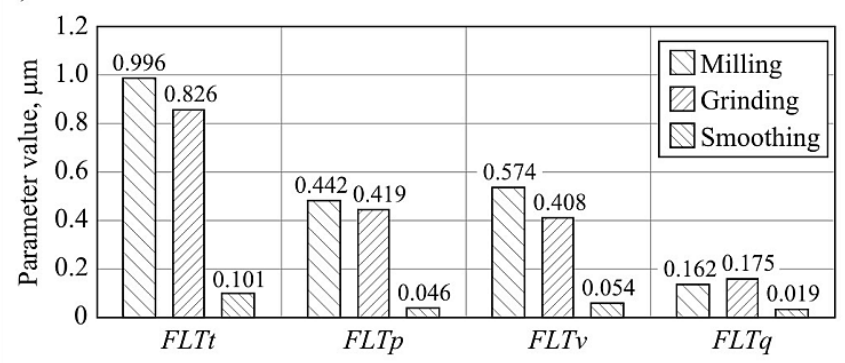

b)

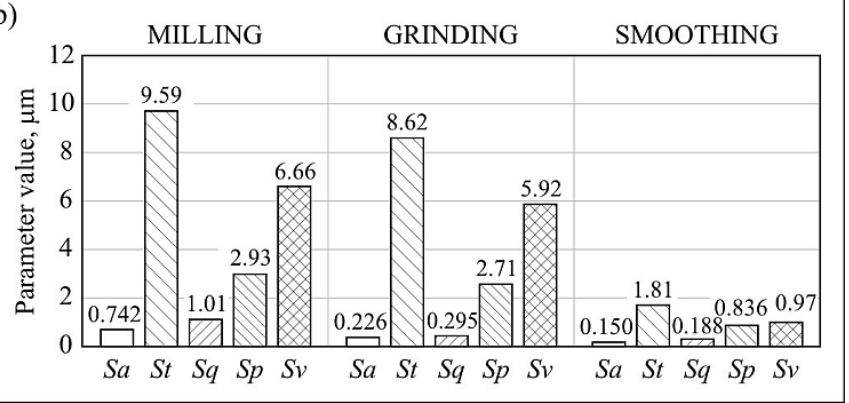

Fig.6. Fluctuations in the values of the flatness parameters (a) and group of primary and secondary surface roughness amplitude parameters (b) for selected machining processes used in experimental investigations.

This issue is especially visible on the machined surface microtopography (Fig.4.e), which is characteristic of surfaces after grinding (with elements as high as 1.0-1.2 $\mu \mathrm{m}$ ). It lacks the smoothed out apexes, typical for such surfaces.

It must therefore be stated that application of the abrasive fabrics, even with low grain granulation, recommended by the producer $(3 \mathrm{M})$ for "smoothing out and polishing large flat surfaces" will not guarantee acquisition of the required quality of the stainless steel surface after machining.
A comparison of all results for smoothing is presented in Fig.4. The results obtained indicate that there was a minor reduction of the surface roughness to the value of $S a=0.150 \mu \mathrm{m}$ and almost 8 -times decrease of the flatness deviation value $F L T t=0.101 \mu \mathrm{m}$.

Despite the considerable reduction of the value of the last parameter, the results need to be considered unfavorable, for the above stated reasons. An overview of the values of other parameters can be obtained in Fig.4.d-e. An analysis of the 
extracted profiles (Fig.4.d) points to a height of their elements, similar to the grinding machining, in the range of $\pm 0.1 \mu \mathrm{m}$.

The groups of analyses presented in Figs.2-4 were complemented with additional data (Fig.5.) including an Abbot-Firestone curve, and graphical study of the $S k$ parameter. The Abbot-Firestone curve, coupled with the depths histogram, is very useful in describing the surface texture of the measured object. The depths histogram presents the density of the distribution of the data points in the analyzed profile. The vertical axis makes it possible to observe the depths, where the horizontal axis is graduated as a $\%$ of the whole population. The Abbott-Firestone curve describes the bearing ratio curve (BRC), which determines the percentage of material traversed in relation to the area covered for a given depth. The vertical axis makes it possible to observe the depths (in the measurement unit), whereas the horizontal axis enables observation of bearing ratio (in $\%$ ).

In the case discussed, for milling (Fig.5.a), relatively large dispersions of the surface roughness heights may be observed, which result from a tool with defined blade shape (mills) generating characteristic machining marks. The total surface roughness height for the shaped surface is $S t=9.59 \mu \mathrm{m}$. This situation is also confirmed by the high values of the functional parameters resulting from graphical studies of the $S k$ parameters.

Application of grinding (Fig.5.b) caused a considerable decrease in the height dispersion (after shaping with a grinding wheel with undefined blade geometry). Nevertheless, it may be observed that there are still occasionally both high apexes and considerable depths in the machined object. This influences the value of the total height of the surface roughness, which is only a little lower than after milling $(S t=8.62 \mu \mathrm{m})$. Analysis of the functional parameters makes it possible to conclude that, after grinding, their values for $S k$, Spk and $S v k$ are lower by 2-, 4- and 3.5- times, respectively, as compared to the values obtained during the previous machining.

Fig.5.c presents results obtained after smoothing. This type of machining made it possible to remove the majority of the apexes protruding over the average plane. This was a result of shaping of the surface with abrasive grains mounted susceptibly within the fabric structure. Moreover, smoothing allowed for decreasing of the whole surface, reducing the depth of the depths upon it. As a result, the total roughness height was considerably reduced. The value of the St parameter was $S t=1.81 \mu \mathrm{m}$, which gives 5- and 4.5 times the reduction of this value, respectively, in relation to milling and grinding. The roughness apexes are spread evenly over the whole height range, which contributes to more advantageous service properties of the surface. The values of the functional parameters were also decreased in this case. Parameters $S k$, Spk and $S v k$ were lowered 1.5-,2and over 2 times, respectively, as compared to the values obtained during grinding.

The fluctuations of values (in the form of a column chart) of the flatness parameters (Fig.6.a) and the group of primary and secondary surface roughness amplitude parameters (Fig.6.b) for selected machining processes used in the experimental investigations were presented in Fig.6. Analysis of the chart presented in Fig.6.a makes it possible to state that the greatest changes in the parameter values are visible for the smoothing process. For parameters FLTt, FLTp, FLTv and FLTq, a 8-, 9-, 7.5 and 9- times decrease of the value, respectively, was observed (as compared with grinding). A similar tendency may be observed by analyzing the chart in Fig.6.b, concerning the group of amplitude surface roughness parameters. For parameters $S a, S t, S q, S p$ and $S v$ a 1.5-, 4-, 1.5-, 3- and 6-times decrease of the value, respectively, was observed (as compared to grinding).

\section{CONCLUSIONS}

The work synthetically presents the results of multicriterion analyses of the quality of the machined surface of X2CrNiMo17-12-2 austenitic stainless steel. What was taken into consideration were the methods for shaping flat surfaces of elements from this material through the operations of milling, grinding and smoothing. One of the most important parameters determining the quality of such shaped surfaces was the value of their flatness deviation. The roughness and load capacity parameters were treated as supplementary data.

Obtained results of simultaneous analysis of individual machining steps (milling, grinding and smoothing) enabled a complementary assessment of the process of shaping the workpiece surface macro- and micro-geometry. Due to the nature of the analyzed machining process (shaping of flat surfaces) a special consideration was given to minimizing the flatness deviations. The presented measurement results show that satisfactorily low values of parameters describing the flatness deviations cannot be achieved without the smoothing process. Only a three-step strategy for the machining of $\mathrm{X} 2 \mathrm{CrNiMo17-12-2}$ steel provided relatively low values of the analyzed parameters, both in terms of roughness and flatness of the machined surface.

The analyses carried out regarding the influence of the typical operations for shaping austenitic stainless steel upon the quality of flat surface created, enabled the following detailed conclusions to be drawn:

- gradual transition from shaping and rough grinding (milling) to operations on the field of rough grinding (grinding and smoothing) allowed for approximately 10 -times the reduction in the values of parameters describing the flatness deviation of the shaped surface;

- obtaining the FLTt parameter value above the level of $0.1 \mu \mathrm{m}$ in the smoothing procedure is considerably hindered when applying abrasive discs made of fabric due to the high flexibility of such tools;

- the discs made from abrasive fabric are very efficient in decreasing the height of roughnesses shaped in the previous machining operations, which allows for obtaining the final parameter value $S a=0.15 \mu \mathrm{m}$ on the surface of the examined elements;

- despite the known difficulties in the machining of austenitic stainless steels, the large volume of intergranular spaces (characteristic for abrasive fabrics) had a positive influence on the effectiveness of smoothing out the machined surface; 
- the analysis of the Abbot-Firestone curve, which determined the surface load capacity, shows that waves characteristic of the carried out machining operations are obtained in subsequent operations;

- the finally obtained geometric structure of the surface was characterized by a relatively even distribution of the roughness apexes, as a result of which the value of the load capacity curve parameter $(S k=0.493 \mu \mathrm{m})$ constituted $27.3 \%$ of the total roughness height of this surface $(S t=1.81 \mu \mathrm{m})$.

\section{ACKNOWLEDGMENTS}

The authors wish to thank Mr. Andrzej Nowicki from Laboratory Team I (Faculty of Mechanical Engineering at Koszalin University of Technology) for preparing the workpiece for machining, Mr. Stanislaw Fronczak for carrying out machining of the workpiece, as well as Mr. Krzysztof Maciejewski from the Laboratory of Metrology and Measurement Systems for measurements of surface microtopography of the workpiece.

\section{REFERENCES}

[1] Niemczewska-Wójcik, M., Sładek, J., Tabaka, M., Wójcik, A. (2012). Product quality assessment measurement and analysis of the surface topography. Metrology and Measurement Systems, 21 (2), 271-280.

[2] Hloch, S., Valicek, J. (2011). Prediction of distribution relationship of titanium surface topography created by abrasive waterjet. International Journal of Surface Science and Engineering, 5 (2-3), 152-168.

[3] Wen, X-L. et al. (2012). Flatness error evaluation and verification based on new generation geometrical product specification (GPS). Precision Engineering, 36 (1), 70-76.

[4] Tolerances of form, orientation - general terms (replace by [14]). PN-78/M-02137.

[5] International Organization for Standardization. (1999). Geometrical Product Specifications (GPS) Geometrical features. Part 1: General terms and definitions. ISO 14660-1:1999.

[6] International Organization for Standardization. (1999). Geometrical Product Specifications (GPS) Geometrical features. Part 2: Extracted median line of a cylinder and a cone, extracted median surface, local size of an extracted feature. ISO 14660-2:1999.

[7] International Organization for Standardization. (2003). Geometrical Products Specifications (GPS) - Flatness - Part 1: Vocabulary and parameters of flatness. ISO/TS 12781-1:2003.

[8] Ricci, F. (2012). Effective Product Lifecycle Management: the role of uncertainties in addressing design, manufacturing and verification processes. $\mathrm{PhD}$ thesis, Polytechnic University of Turin, Turin, Italy. http://porto.polito.it/2501694/1/Tesi_Ricci.pdf
[9] Calvo, R., Gómez, E., Domingo, R. (2014). Vectorial method of minimum zone tolerance for flatness, straightness, and their uncertainty estimation. International Journal of Precision Engineering and Manufacturing, 15 (1), 31-44.

[10] Ilyas Khan, M., Ma, S.Y. (2014). Efficient genetic algorithms for measurement of flatness error and development of flatness plane based on minimum zone method. Advanced Materials Research, 941, 22322238.

[11] Ye, R.F. et al. (2012). Minimum zone evaluation of flatness error using an adaptive iterative strategy for coordinate measuring machines data. Advanced Materials Research, 472, 25-29.

[12] Ren, M.J., Cheung, C.F., Kong, L.B. (2012). A task specific uncertainty analysis method for least-squaresbased form characterization of ultra-precision freeform surfaces. Measurement Science and Technology, 23 (5), 054005.

[13] He, G. et al. (2014). Conicity error evaluation using sequential quadratic programming algorithm. Precision Engineering, 38 (2), 330-336.

[14] International Organization for Standardization. (2006). Geometrical Product Specifications (GPS) Geometrical tolerancing - Tolerances of form, orientation, location and run-out. UNE-EN ISO 1101:2006.

[15] Lakota, S., Görög, A. (2011). Flatness measurement by multi-point methods and by scanning methods. $A d$ Alta: Journal of Interdisciplinary Research, 1 (1), 124127.

[16] Skibicki, D., Sempruch, J., Pejkowski, L. (2012). Steel $\mathrm{X} 2 \mathrm{CrNiMo17-12-2}$ Testing for uniaxial, proportional and non-proportional loads as delivered and in the annealed condition. Materials Science Forum, 726, 171-180.

[17] Dobrzański, L.A., Brytan, Z., Rosso, M. (2007). Sinter-hardening process applicable to stainless steels. Journal of Achievements in Materials and Manufacturing Engineering, 24 (2), 11-18.

[18] Deutsche Edelstahlwerke GmbH. (2008). Nichtrostender austenitischer Stahl X2CrNiMo17-122. http://www.dew-stahl.com/fileadmin/files/ dewstahl.com/documents/Publikationen/ Werkstoffdatenblaetter/RSH/1.4404_de.pdf

[19] Stout, K.J. et al. (1993). The Development of Methods for the Characterization of Roughness in Three Dimensions. Publication No. EUR 15178 EN (Final Report) BCR. Brussels, Belgium: European Community.

Received November 19, 2013. Accepted July 31, 2014. 